\title{
Controlled Electroless Deposition of Noble Metal Nanoparticle Films on Germanium Surfaces
}

2002

Vol. 2, No. 10 1067-1071

\author{
Lon A. Porter, Jr., Hee Cheul Choi, Alexander E. Ribbe, and Jillian M. Buriak* \\ Department of Chemistry, 1393 Brown Laboratories of Chemistry, Purdue University, \\ West Lafayette, Indiana 47907-1393
}

Received July 2, 2002; Revised Manuscript Received August 8, 2002

\begin{abstract}
Thin noble metal films have been prepared as a result of the immersion of germanium substrates into dilute, aqueous solutions of $\mathrm{AuCl}_{4}{ }^{-}$, $\mathrm{PdCl}_{4}{ }^{2-}$, or $\mathrm{PtCl}_{4}{ }^{2-}$, respectively. Deposition proceeds via galvanic displacement in the absence of fluoride, pH adjusters, complexing agents, or external reducing agents. This manner of metal deposition serves as a cost-effective, high-throughput methodology with control over surface morphology and deposition rate by modulation of plating parameters such as concentration, temperature, and immersion time.
\end{abstract}

Recent progress toward metallization on the diminishing size regimes dictated by the feverishly evolving disciplines of nanotechnology has imposed increasingly stringent demands upon thin film preparation methodologies. ${ }^{1}$ Ultra large scale integration (ULSI) device fabrication, nanoelectromechanical systems (NEMS), and arrayed nanosensors will require unparalleled control of metal film surface morphology, deposition rate, and substrate adhesion without sacrificing throughput or cost effectiveness. Furthermore, noble metal films of this type are important for fundamental investigations aimed at elucidating the intricate nature of interfacial topics ranging from self-assembled monolayers (SAMs) to sensing and heterogeneous catalysis. ${ }^{2-8}$ In contrast to complex and expensive vacuum methods of metallization, research in our laboratory has focused on the preparation of noble metal thin films on semiconductor substrates via electroless deposition. Herein we describe the implementation of this facile methodology to prepare nanostructured, high surface area noble metal films with control over surface morphology and deposition rate. Moreover, metal films prepared in this manner exhibit excellent adhesion to the underlying semiconductor substrate.

"Electroless" plating is a term coined by Brenner and Riddell $^{9}$ to describe the spontaneous reduction of metal ions to metallic particles and films in the absence of an external source of electric current. ${ }^{10}$ This method has attracted great interest due to simplicity of operation, cost effectiveness, high throughput, and lack of elaborate equipment. ${ }^{10-12}$ Electroless deposition is applicable to a wide range of metal/ substrate combinations, including metal-on-metal, metal-onsemiconductor, and metal-on-insulator. This is particularly

\footnotetext{
* Corresponding author. E-mail: buriak@purdue.edu.
}

(a)

(b)
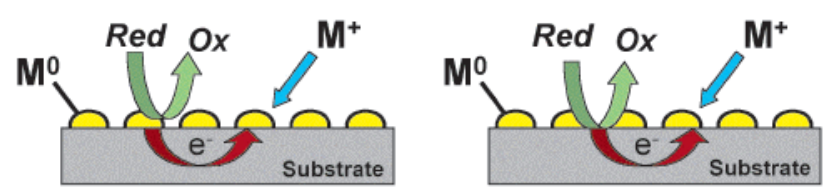

(c)

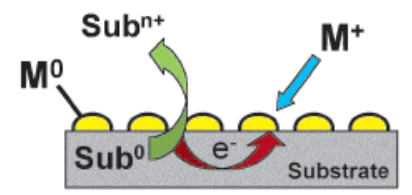

Figure 1. Electroless deposition processes: (a) Autocatalytic: The reduced noble metal serves as the catalyst for further reduction of the metal salt by the external reducing agent. Thick layers are possible. (b) Substrate catalyzed: The substrate surface catalyzes the reduction of the metal salt by the reducing agent. Upon deposition of a complete film, reduction ceases because the substrate is no longer exposed. (c) Galvanic displacement: The surface serves as the reducing agent and electron source for reduction of the metal salt. Deposition can continue as long as ions can permeate and electrons can transfer through the film.

important with regard to metal deposition on electronically isolated substrate regions, such as those on a circuit board, for example. The literature commonly utilizes the term "electroless deposition" interchangeably to describe three fundamentally different plating mechanisms (Figure 1). ${ }^{11}$ These include autocatalytic, substrate catalyzed, and galvanic displacement (immersion) processes. Autocatalytic plating baths are commonly employed in electronics fabrication and typically contain a metal salt, $\mathrm{pH}$ adjuster, complexing agent, reducing agent, and other various additives. ${ }^{12}$ Once initiated, the reduced metal species serves to catalyze subsequent metal 
Table 1: Mixed Potential Theory Predictions for Spontaneous Metal Deposition Candidates for Galvanic Displacement on Germanium, with Values Referenced to NHE ${ }^{10,16,17}$

\begin{tabular}{cllc}
\hline system & \multicolumn{1}{c}{ redox couple } & $\mathrm{E}^{\circ}(\mathrm{V})^{\mathrm{a}}$ & $\mathrm{E}_{\text {cell }}^{\circ}(\mathrm{V})^{\mathrm{a}}$ \\
\hline $\mathrm{Au} / \mathrm{Ge}$ & $\mathrm{AuCl}_{4}{ }^{-}+3 \mathrm{e}^{-} \rightarrow \mathrm{Au}+4 \mathrm{Cl}^{-}$ & +1.002 & +0.878 \\
& $\mathrm{Ge} \rightarrow \mathrm{Ge}^{4+}+4 \mathrm{e}^{-}$ & -0.124 & \\
$\mathrm{Pd} / \mathrm{Ge}$ & $\mathrm{PdCl}_{4}{ }^{2-}+2 \mathrm{e}^{-} \rightarrow \mathrm{Pd}+4 \mathrm{Cl}^{-}$ & +0.62 & +0.50 \\
& $\mathrm{Ge} \rightarrow \mathrm{Ge}^{4+}+4 \mathrm{e}^{-}$ & -0.124 & \\
$\mathrm{Pt} / \mathrm{Ge}$ & $\mathrm{PtCl}_{4}^{2-}+2 \mathrm{e}^{-} \rightarrow \mathrm{Pt}+4 \mathrm{Cl}^{-}$ & +0.758 & +0.634 \\
& $\mathrm{Ge} \rightarrow \mathrm{Ge}^{4+}+4 \mathrm{e}^{-}$ & -0.124 &
\end{tabular}

${ }^{a}$ The individual half-cell potentials are listed in the column headed by $E^{\circ}(\mathrm{V})$. The combination of these two values leads to the overall $E_{\text {cell }}^{\circ}(\mathrm{V})$ of the reaction.

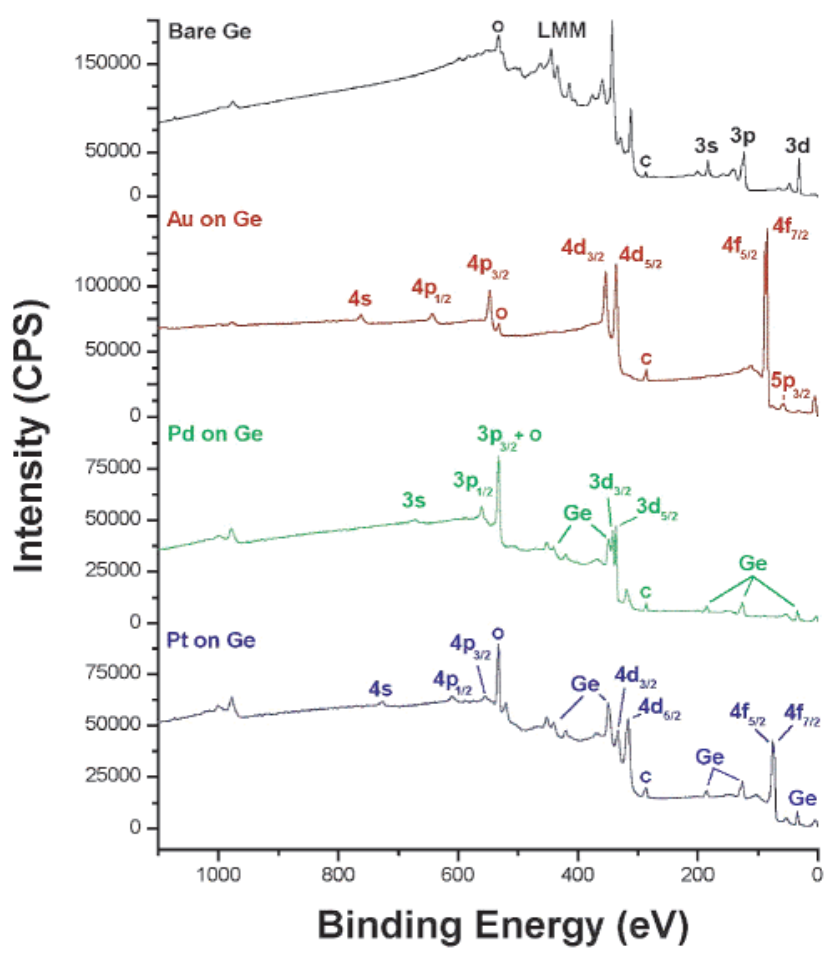

Figure 2. XPS spectra of gold, palladium, and platinum deposited on $\mathrm{Ge}(100)$ from $1.0 \mathrm{mM}$ solutions of $\mathrm{AuCl}_{4}{ }^{-}, \mathrm{PdCl}_{4}{ }^{2-}, \mathrm{PtCl}_{4}{ }^{2-}$ for $60 \mathrm{~min}$, respectively. Binding energies are consistent with those for the metallic state.

reduction (Figure 1a). Similarly, substrate catalyzed deposition baths also contain a metal salt and reducing agent, but metal reduction is facilitated on the substrate surface, and once completely coated, metal ions cease to be reduced from solution (Figure 1b) ${ }^{13,14}$ Galvanic displacement proceeds in an entirely different manner, in that deposition is carried out in the absence of an external reducing agent (Figure 1c); ${ }^{11}$ the reducing electrons are derived from the bonding electrons of the substrate lattice (valence band). ${ }^{15}$ Deposition proceeds as long as oxidized substrate ions are able to permeate through the metal film into solution, or until a dielectric layer of oxidized substrate forms, thereby halting electron transfer. Although the detailed mechanism of galvanic displacement is not fully understood, mixed potential theory ${ }^{10,16}$ provides a useful tool to predict reactivities of metal/substrate systems. The metals employed in this work (gold, palladium, and platinum) were selected on this basis. ${ }^{17,18}$ Table 1 lists three

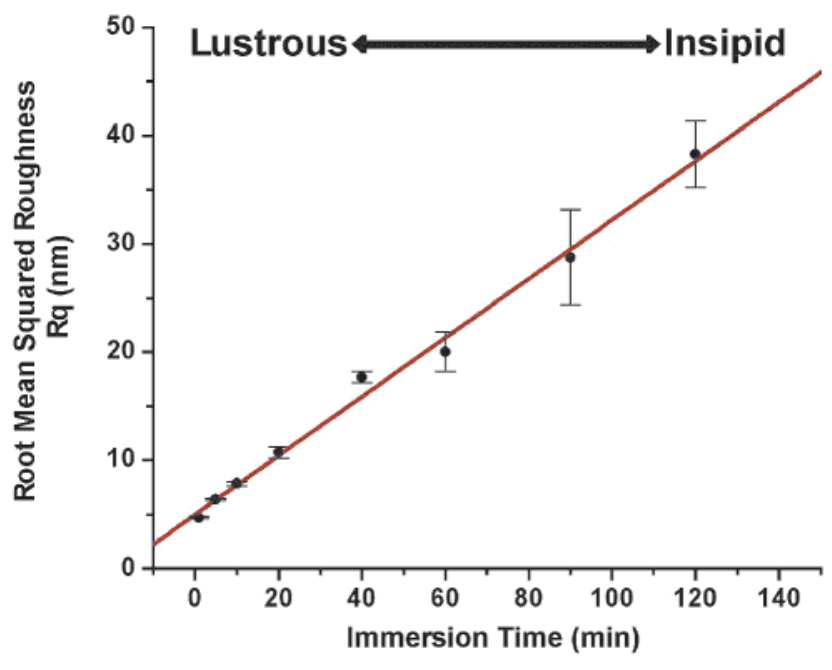

Figure 3. Effect of immersion times on surface roughness for electroless deposition of gold on $\mathrm{Ge}(100)$ from a $1.0 \mathrm{mM}$ solution of $\mathrm{AuCl}_{4}{ }^{-}$at $25^{\circ} \mathrm{C}$. Brief immersion times yielded highly reflective, lustrous surfaces, whereas more lengthy immersion times resulted in rougher surfaces, insipid in appearance.

(a)

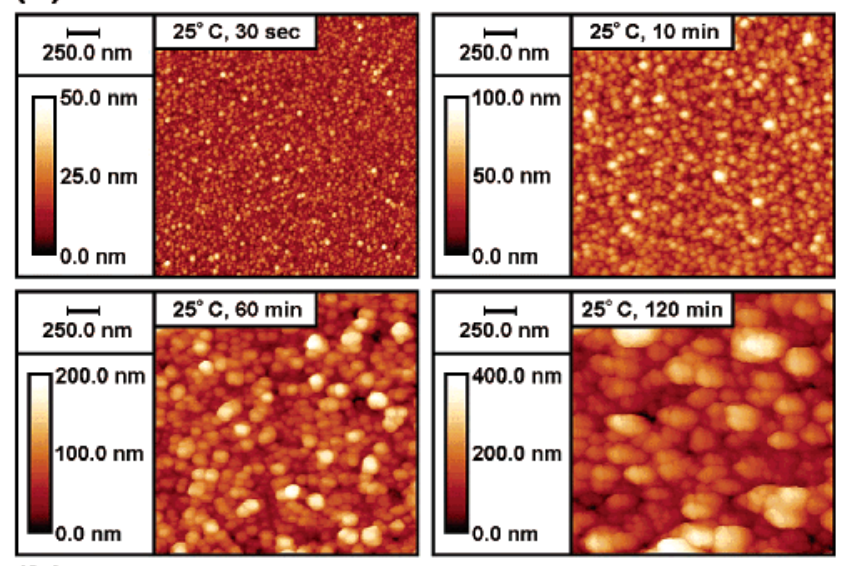

(b)

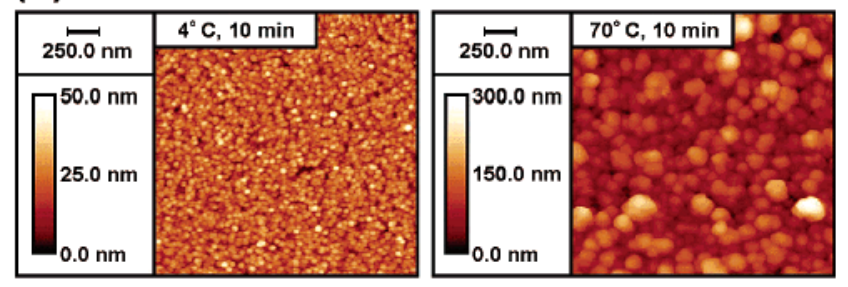

Figure 4. Tapping mode atomic force micrographs of $\mathrm{Ge}(100)$ immersed into $1.0 \mathrm{mM} \mathrm{AuCl}_{4}{ }^{-}$(a) for increasing immersion times at $25^{\circ} \mathrm{C}$ and (b) for a $10 \mathrm{~min}$ immersion at $4{ }^{\circ} \mathrm{C}$ and $70{ }^{\circ} \mathrm{C}$. Grain sizes and deposition rate may be tailored through careful control of immersion time and plating bath temperature.

examples that lead to a positive $E_{\text {cell }}^{\circ}$, which indicates a spontaneous reaction, not requiring any external electron source. In theory, however, any metal with a sufficiently positive redox potential is a candidate for deposition via galvanic displacement.

Galvanic displacement of metal ions from hydrofluoric acid solutions onto semiconductors initially posed a formidable barrier to electronics fabrication. Metallic ion impurities in HF oxide etching baths were found to deposit onto silicon, 
(a)

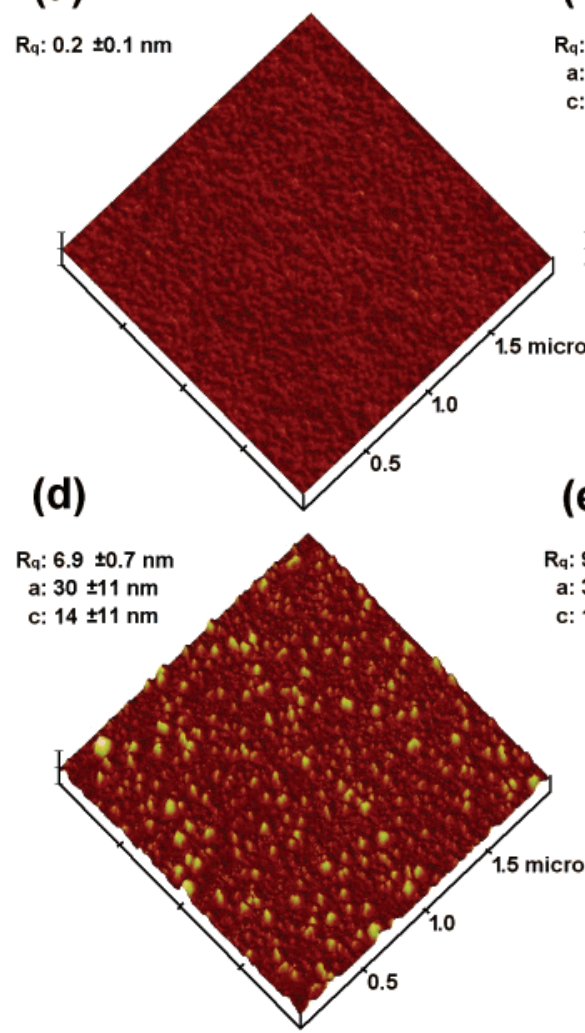

(b)

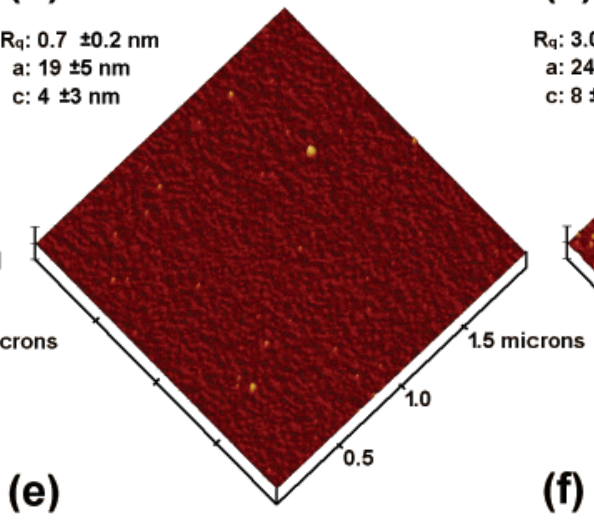

(f)

(c)

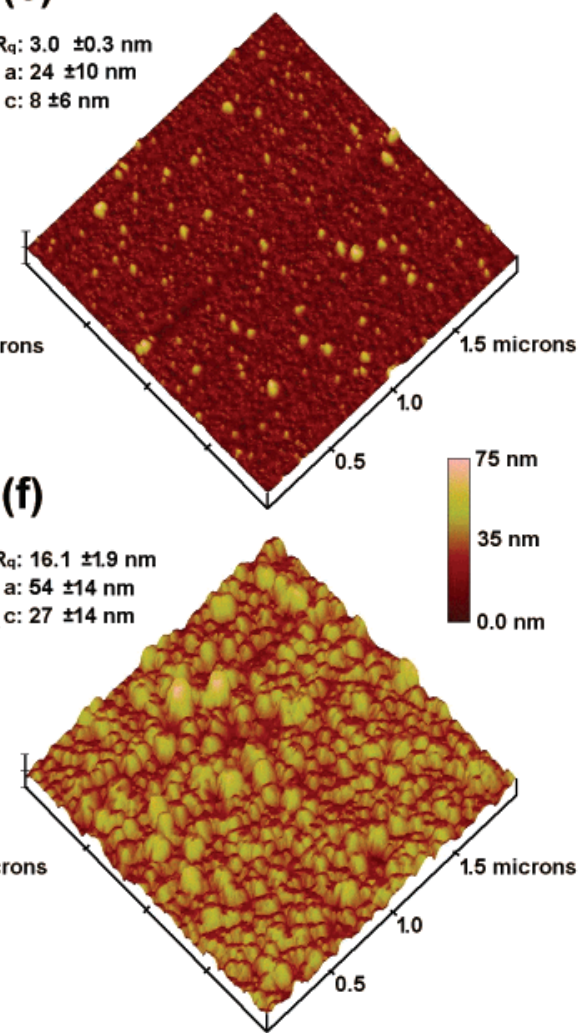

Figure 5. Tapping mode atomic force micrographs of various immersion times of $\mathrm{Ge}(100)$ in $0.1 \mathrm{mM} \mathrm{AuCl}{ }_{4}^{-}$: (a) $\mathrm{Bare} \mathrm{Ge}_{(100)}$; (b) 5 s; (c) $1 \mathrm{~min}$; (d) $10 \mathrm{~min}$; (e) $60 \mathrm{~min}$; (f) $500 \mathrm{~min}$. Evidence for a 3D island growth mechanism was observed as metal deposition progressed and randomly distributed nucleation sites coalesced to yield a continuous film.

thereby compromising device performance. However, recent work has focused upon controlled galvanic displacement as a metallization method competitive with state of the art physical and electrochemical deposition methods. ${ }^{15}$ Because prior investigations have demonstrated metal adhesion problems with the silicon case, we have limited our studies to germanium. ${ }^{18-20}$ Germanium is of interest for technological applications because germanium layers on silicon are easily fabricated via thermal evaporation methods, and silicon-germanium heterostructures are predicted to have potential in high-speed optoelectronic applications. ${ }^{21}$ While the vast majority of deposition bath solutions contain hydrofluoric acid as a major component, ${ }^{22-24}$ recent findings in our laboratory have discovered noble metal deposition on germanium in the absence of toxic HF. The use of HF is unnecessary due to the fact that germanium oxide is soluble in water, in contrast to the silicon case. ${ }^{25}$ Likewise, the addition of $\mathrm{pH}$ adjusters, complexing agents, or any other additive is unnecessary.

Electroless deposition of noble metal films on germanium substrates is accomplished via immersion of the native oxidecapped wafer into a $1.0 \mathrm{mM}$ aqueous solution of $\mathrm{AuCl}_{4}{ }^{-}$, $\mathrm{PdCl}_{4}{ }^{2-}$, or $\mathrm{PtCl}_{4}{ }^{2-}$. Following electroless deposition, the substrates were removed from the plating baths and washed with water, ethanol, and pentane. The samples were then dried under a steady stream of nitrogen. The elemental composition of these films was confirmed by X-ray photoelectron spectroscopy (XPS) (Figure 2) ${ }^{26}$ In the case of gold, nanocrystallite films form spontaneously by immersion of a degreased germanium wafer (100 orientation, intrinsic, n-, or p-type) for $30 \mathrm{~s}$. Atomic force microscopy (AFM) revealed the thin gold film to be continuous and nanostructured, with grain sizes on the order of $30 \mathrm{~nm}$. This grain size is in the same size regime observed for thin metal films produced by utilizing conventional vacuum evaporation techniques. The gold deposition rate was determined to be approximately 1.6 $\mathrm{nm} / \mathrm{min}$ at room temperature.

Grain sizes and film thicknesses were determined to increase with longer immersion times. Shorter immersion times ( $<60 \mathrm{~min}$ ) result in lustrous yellow films, due to highly reflective, smooth surfaces composed of small grains. ${ }^{27}$ These films adhered firmly to the Ge substrate. The films withstand 10 min of sonication in water and do not peel off with tape. More lengthy plating times ( $>60 \mathrm{~min}$ ) resulted in thick films, insipid in appearance (Figure 3). The larger grain sizes produced from lengthy immersion times produced rougher surfaces, leading to increased light scattering. Mean grain size was observed to increase from $31 \pm 10 \mathrm{~nm}$ for a $30 \mathrm{~s}$ immersion to $160 \pm 57 \mathrm{~nm}$ for a $120 \mathrm{~min}$ immersion (Figure 4a). Extremely thick films produced from immersion times longer than 120 min withstand solvent washing, but are removed with tape. Illumination with white light (W source) during deposition appears to affect neither the rate nor morphology of the resulting metal films.

Grain sizes and deposition rates were also controlled through careful modulation of both the temperature and 


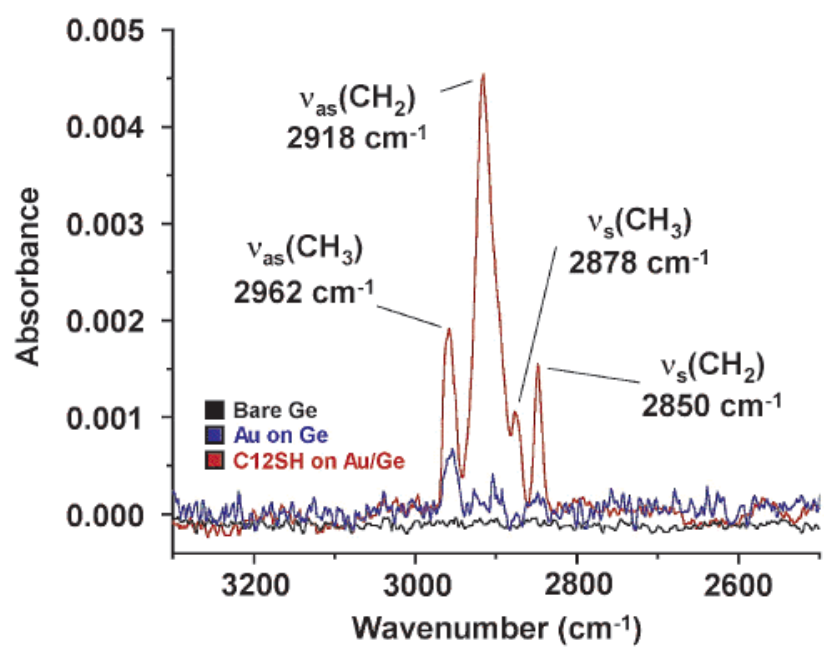

Figure 6. Transmission FTIR spectrum of the $\mathrm{C}-\mathrm{H}$ stretching region for dodecanthiolate-capped $\mathrm{Au}$ on $\mathrm{Ge}(100)$. The large surface area exhibited by these surfaces provides a facile route to SAM characterization via FTIR.

concentration of the deposition bath. For example, gold films produced from a $10 \mathrm{~min}$ immersion in $1 \mathrm{mM} \mathrm{AuCl}_{4}{ }^{-}$at 4 ${ }^{\circ} \mathrm{C}$ yield grains on the order of $20 \mathrm{~nm}$, whereas those produced at $70{ }^{\circ} \mathrm{C}$ are nearly $120 \mathrm{~nm}$ (Figure 4b). This temperature dependence is similar with respect to deposition rate. The deposition rate slowed to $1 \mathrm{~nm} / \mathrm{min}$ at $4{ }^{\circ} \mathrm{C}$ and was accelerated to nearly $20 \mathrm{~nm} / \mathrm{min}$ at $70{ }^{\circ} \mathrm{C}$. Increasing the concentration of the metal ion in solution also resulted in an increase in grain size and deposition rate (Supporting Information). A short, ten-minute immersion of Ge into a $10 \mathrm{mM} \mathrm{AuCl}_{4}{ }^{-}$solution produced a film composed of $\sim 150$ $\mathrm{nm}$ grains. This grain size is analogous to that produced from a lengthy $120 \mathrm{~min}$ immersion in $1.0 \mathrm{mM} \mathrm{AuCl}_{4}{ }^{-}$. The film deposited from the $10 \mathrm{mM}$ solution, however, was significantly rougher $\left(R_{\mathrm{q}}=67 \pm 11 \mathrm{~nm}\right)$ than the film prepared from the $1.0 \mathrm{mM} \mathrm{AuCl}_{4}^{-}$solution. The same $10 \mathrm{~min}$ immersion into $100 \mathrm{mM} \mathrm{AuCl}_{4}{ }^{-}$resulted in a gold film composed of microcrystalline grains, each in excess of one micron in diameter. Films of palladium and platinum are prepared in an analogous fashion with grain sizes and deposition rates correspondingly affected by controlling plating conditions such as metal concentration, temperature, and immersion time.

The rate of nucleation and ensuing film growth for gold deposition on germanium from a $1.0 \mathrm{mM} \mathrm{AuCl}_{4}{ }^{-}$solution is rapid. Nucleation sites are occupied within $\sim 15 \mathrm{~s}$ of immersion, proceeding to form an initial metal layer through island growth, followed quickly by overlayer growth. While this concentration provides continuous films expediently, it sheds little light on the fundamental mechanism driving the electroless deposition. To explore the initial stages of gold nucleation and subsequent nanocrystallite growth, a $0.1 \mathrm{mM}$ solution of $\mathrm{AuCl}_{4}{ }^{-}$was utilized (Figure 5). Atomic force microscopy, operated in tapping mode revealed the formation of gold nanocrystallites within $5 \mathrm{~s}$ of substrate immersion. The randomly distributed gold islands are best approximated as oblate hemispheroids (hemispherical solids with depressed polar radii). ${ }^{28}$ These initial grains, with a mean equatorial radius (a) of $19 \pm 5 \mathrm{~nm}$ and polar radius (c) of $4 \pm 3 \mathrm{~nm}$ are significantly oblate $(a / c=5)$. Utilizing standard geometric relationships, the mean surface area, volume, and mass were calculated for these nanocrystallites (Supporting Information). AFM images taken at longer immersion times reveal further evidence for film growth through a VolmerWeber (3D island growth) mechanism. Although grain equatorial and polar radii both increase with immersion time, the grains become more spherical (less oblate) with time. After nearly 60 min of deposition, a continuous gold layer is observed. As electroless deposition continues, the film thickens and grain sizes increase. Following $500 \mathrm{~min}$ of immersion, multilayer growth is evident, and grain agglomeration as a consequence of Ostwald ripening is observed. ${ }^{29}$

Complex multilayer growth is further supported for longer immersion times through the preparation of self-assembled monolayers of alkanethiols on gold. A sample of gold on germanium formed from $500 \mathrm{~min}$ immersion in $0.1 \mathrm{~mm}$ $\mathrm{AuCl}_{4}{ }^{-}$was soaked in a $1 \mathrm{mM}$ ethanolic solution of dodecanethiol for $24 \mathrm{~h}$. The functionalized gold surface was characterized via transmission mode Fourier transform infrared spectroscopy (FTIR). After 512 scans, the $\mathrm{C}-\mathrm{H}$ stretching frequencies indicative of closely packed monolayers were clearly resolved, owing to the large surface area resulting from the gold multilayer growth (Figure 6). ${ }^{30}$ Organothiol monolayer formation also increases the level of complexity of the system and allows for interfacing of the wide range of organic and biological thiol-containing molelcules.

Analogous evidence in support of the island growth mechanism was observed in the formation of Pd and Pt films on Ge (Figure 7). Nucleation and grain growth was markedly slower for $\mathrm{Pd}$ and $\mathrm{Pt}$ in comparison to $\mathrm{Au}$, therefore $1.0 \mathrm{mM}$ solutions of $\mathrm{PdCl}_{4}{ }^{2-}$ and $\mathrm{PtCl}_{4}{ }^{2-}$ were employed. Scanning electron microscopy revealed the growth of large metallic islands, randomly distributed over the germanium surface. Nucleation continued to slowly progress on the surface as other grains grew, taking considerably longer to yield a continuous metallic film. Nearly $120 \mathrm{~min}$ of immersion was required for both metals. The resultant films consisted of nanoparticulate grains, producing multilayered structures with large surface areas for extended deposition times.

The mechanism for the galvanic displacement reaction on Ge with Au, Pd, and Pt salts, species derived from metals with highly positive equilibrium reduction potentials, is expected to occur via hole injection into the valence band. ${ }^{15}$ Therefore, germanium-germanium bonds supply the electrons used to reduce the metal salts on the surface, leading to subsequent dissolution of the germanium substrate as the oxide. ${ }^{18}$ This would explain the lack of dependence upon semiconductor doping and light illumination. It remains to be determined if the oxidation and dissolution of the substrate occur from beneath the metal deposits or alongside; the postulated formation of chemical bonds at the $\mathrm{Au}-\mathrm{Ge}$ interface and enhanced film adhesion suggest that the latter may be dominant. ${ }^{18}$

In summary, electroless deposition of noble metal salts on germanium leads to morphologically complex nanostruc- 
(a)

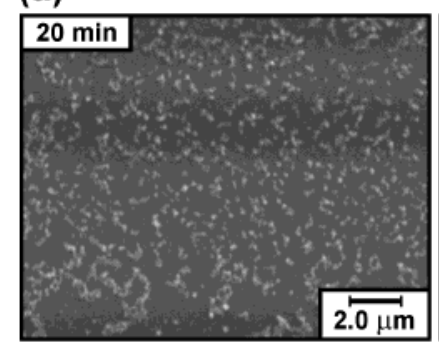

(b)
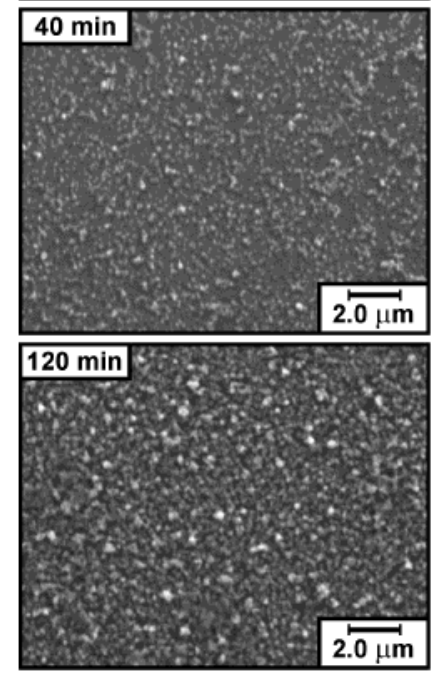
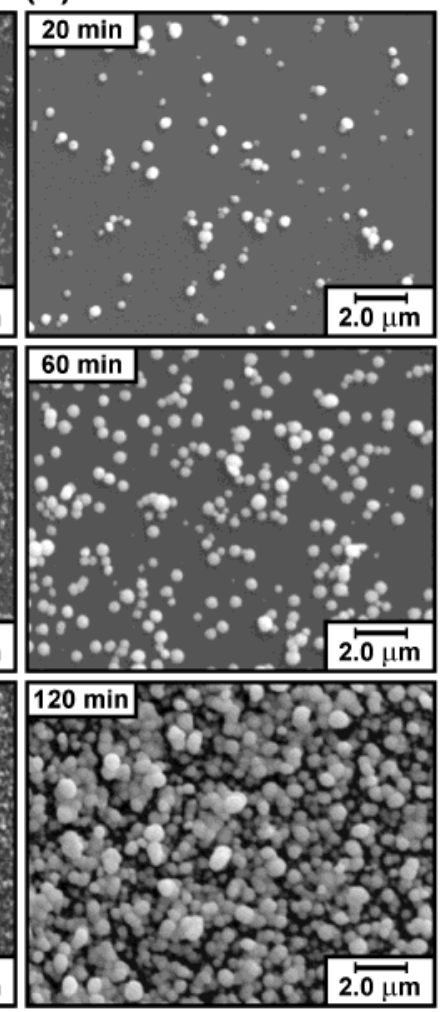

Figure 7. Scanning electron micrographs of (a) Pd deposited on $\mathrm{Ge}(100)$ from $1.0 \mathrm{mM} \mathrm{PdCl}{ }^{2-}$ at $25^{\circ} \mathrm{C}$ and (b) Pt deposited on $\mathrm{Ge}(100)$ from $1.0 \mathrm{mM} \mathrm{PtCl} 4^{2-}$ at $25{ }^{\circ} \mathrm{C}$. Deposition rates for $\mathrm{Pd}$ and $\mathrm{Pt}$ were found to be significantly slower than that of $\mathrm{Au}$ at equivalent metal salt concentrations.

tured metallic films. Deposition proceeds via galvanic displacement in the absence of fluoride, $\mathrm{pH}$ adjusters, complexing agents, or external reducing agents. This facile methodology provides control over surface morphology and deposition rate by careful modulation of plating parameters such as metal ion concentration, temperature, and immersion time. Future studies will focus on incorporating this method into current micro- and nanolithographic technologies. The extent of molecular contact between the metal deposits and the underlying substrate will be investigated through scanning tunneling spectroscopy (STS) to determine their utility as nanoscale electrical contacts for interfacing a range of different organic and biomolecules, and for catalytic applications, among others.

Acknowledgment. We gratefully acknowledge support from NSF for grants CHE-9875150 and CHE-0110846 and a predoctoral fellowship to LAP, the Purdue Research Foundation (fellowship to H.C.C.) and Purdue University. J.M.B. is the holder of a Sloan Research Fellowship (20002002), a Camille and Henry Dreyfus Teacher-Scholar Award

(2002-2004), and is a Cottrell Teacher-Scholar of Research Corporation (2000-2002). We acknowledge the Purdue Laboratory of Chemical Nanotechnology for technical support and expert advice. Dr. Richard T Haasch is acknowledged for the acquisition of XPS data, carried out at the Center for Microanalysis of Materials, University of Illinois, which is partially supported by the U.S. Department of Energy under grant DEFG02-96-ER45439.

Supporting Information Available: Detailed experimental procedures for wafer degreasing and noble film deposition along with additional micrographs and analysis of grain and film growth. This material is available free of charge via the Internet at http://www.pubs.acs.org.

\section{References}

(1) Murarka, S. P. Metallization; Butterworth-Heineman: Stoneham, MA, 1993.

(2) St. John, J. Noble Metals; Time-Life: Alexandria, VA, 1984.

(3) Ulman, A. Chem. Rev. 1996, 96, 1533.

(4) Goodman, P. Gold Bull. 2002, 35, 21.

(5) Kacer, P.; Cerveny, L. Appl. Catal. A 2002, 229, 193.

(6) Shipway, A. N.; Katz, E.; Willner, I. ChemPhysChem. 2000, 1, 18.

(7) van Noort, D.; Mandenius, C.-F. Biosens. Bioelectron. 2000, 15, 203.

(8) Johne, B.; Hansen, K.; Mork, E.; Holtlund, J. J. Immun. Methods 1995, 183, 167.

(9) Brenner, A.; Riddell, E. J. Res. Natl. Bur. Std. 1946, 37, 31.

(10) Okinaka, Y.; Osaka, T. Adv. Electrochem. Sci. Eng. 1994, 3, 55.

(11) Okinaka, Y.; Hoshino, M. Gold Bull. 1998, 31, 3.

(12) Electroless Plating: Fundamentals and Applications; Mallory, G. O., Hajdu, J. B., Eds.; AESF: Orlando, FL, 1990.

(13) Kato, M.; Sato, J.; Otani, H.; Homma, T.; Okinaka, Y.; Yoshioka, O. J. Electrochem. Soc. 2002, 149, C164.

(14) Sato, J.; Kato, M.; Otani, H.; Homma, T.; Okinaka, Y.; Yoshioka O. J. Electrochem. Soc. 2002, 149, C168.

(15) Oskam, G.; Long, J. G.; Natarajan, A.; Searson, P. C. J. Phys. D 1998, 31, 1927.

(16) Jones, D. A. Principles and Prenvention of Corrosion; Macmillan: New York, 1992.

(17) Bard, A. J.; Parsons, R.; Jordan, J. Standard Potentials in Aqueous Solution; Marcel Dekker Inc.: New York, 1985.

(18) Magagnin, L.; Maboudian, R.; Carraro, C. J. Phys. Chem. B 2002 , 106, 401.

(19) Magagnin, L.; Maboudian, R.; Carraro, C. Electrochem. Solid-State Lett. 2001, 1, C5.

(20) Rossiter, C.; Suni, I. I. Surf. Sci. 1999, L553.

(21) Paul, D. J. Phys. World 2000, 13, 27.

(22) Nagahara, L. A.; Ohmori, T.; Hashimoto, K.; Fujishima, A. J. Vac. Sci. Technol. A 1993, 11, 763.

(23) Balashova, N. A.; Eletskii, V. V.; Medyntsev, V. V. Elektrokhim. 1965, 1(3), 235.

(24) Krikshtopaitis, I. B.; Kudzhmauskaite, Z. P. Elektrokhim. 1971, 7(10), 1529.

(25) The solubility of $\mathrm{GeO}_{2}$ in cold water is $10 \mathrm{~g} / \mathrm{L}$. Glockling, F. The Chemistry of Germanium; Academic Press: London, 1969.

(26) Handbook of X-ray Photoelectron Spectroscopy; Muilenberg, G. E., Ed.; Perkin-Elmer Corporation: Eden Prairie, MN, 1985.

(27) Bartlett, N. Gold Bull. 1998, 31, 22.

(28) Hilbert, D.; Chon-Vossen, S. Geometry and the Imagination; Chelsea: New York, 1999.

(29) Boistelle, R.; Astier, J. P. J. Cryst. Growth 1988, 90, 14.

(30) Porter, L. A., Jr.; Ji, D.; Westcott, S. L.; Graupe, M.; Czernuszewicz, R. S.; Halas, N. J.; Lee, T. R. Langmuir 1998, 14, 7378.

NL025677U 